\title{
Children Philosophize: the Revival of an Ancient Greek Ideal
}

\section{Mateusz Bonecki, Eva Marsal, Ewa Nowak, Barbara Weber}

Promoting philosophical and ethical education in schools requires academic education of teacher candidates who are able to apply professional methods. In schools, information pills in contrast to the academy, advice philosophy and ethics need to be taught in a practical and interactive way. ?Learning-by-doing?, more about as distinguished from philosophy according to the ?scholastic concept?. Philosophy according to the ?universal concept? deals with questions generally asked not only by philosophers, but by all thinking people. In Kant?s view, every person is capable of reflecting on life?s great and important questions. The Enlightenment was shaped by his challenge: ?Have the courage use your own reason (sapere aude)?. All questions resulting from this, according to Kant, can be summed up in four fundamental questions: ?What can I know? What ought I do? What may I hope for? What is a human being?? Even though Kant himself certainly did not have the thinking of children in mind when he wrote these words, anyone who deals with children knows that they ask big questions which lead in similar directions. ?Why is there often injustice in the world?? ?Where do people go when they die?? ?Will I still be the same person when I grow up?? It is characteristic of these great questions that they are as old as humanity. No final answer exists, and each person must set out anew to find provisional answers. The search is helpful to the individual in forming personal values and convictions. For this reason, the process of philosophizing together is shaped by an attitude of mutual respect. The process of cooperative thinking is characterized by curiosity and openness, but even more by the will to understand and be understood.

In order to implement the purpose of the teaching and learning strategy on Philosophizing with Children at the University of Poznan (AMU, Poland) the Chair of Ethics organized the double-workshop ?Children Philosophize? (on 2011, May \& August) and the symposium, both supported by Akademicki Poznań 2011. Our special guests Professor Eva Marsal (Karlsruhe, Germany), Professor Barbara Weber (Vancouver, Canada / Regensburg, Germany) and Professor Andrew Wierciński (Freiburg/Br., Germany / Lublin, Poland) were going to promote the didactic skills in the domain of philosophical-ethical reasoning, judging, and discussion in participants. The initiators are especially interested in development of free discourse and democratic quality of Middle-European education, in promotion of philosophical-ethical reflective competency, and in establishing of new teaching standards for philosophy and ethics (free discourse, full inclusion, cooperative inquiry instead of an authoritarian frontal teaching way etc.), tolerance and respect vis-?-vis the uniqueness of others and their individual thinkingways, while at the same time supporting opportunities for critical and open-minded thinking.

They offer a free discourse space to their future pupils and students, in which they will facilitate independent thinking and judging. Of prime importance in this regard are Community of Inquiry (M. Lipman, D. Kennedy) and Five-Fingers Method (E. Martens) that are efficient in the philosophical and ethical education.

The ?Children Philosophize? Project seems to be truly fruitful for participants (mostly academic teachers and PhD candidates) and they wish to continue our workshops in the hopes of meeting new colleagues as well (registration and deadlines on ethics.amu.edu.pl).

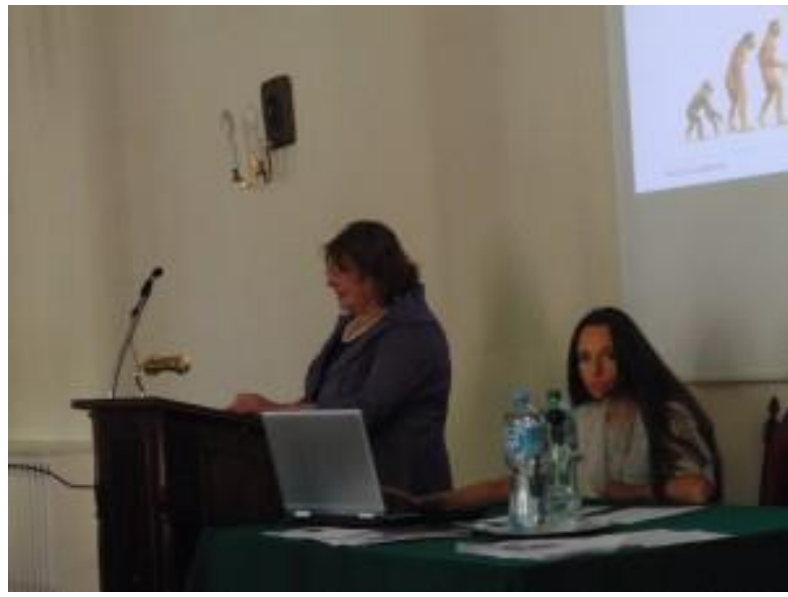

1. Professor Eva Marsal \& Professor Barbara Weber: May-Symposium. 


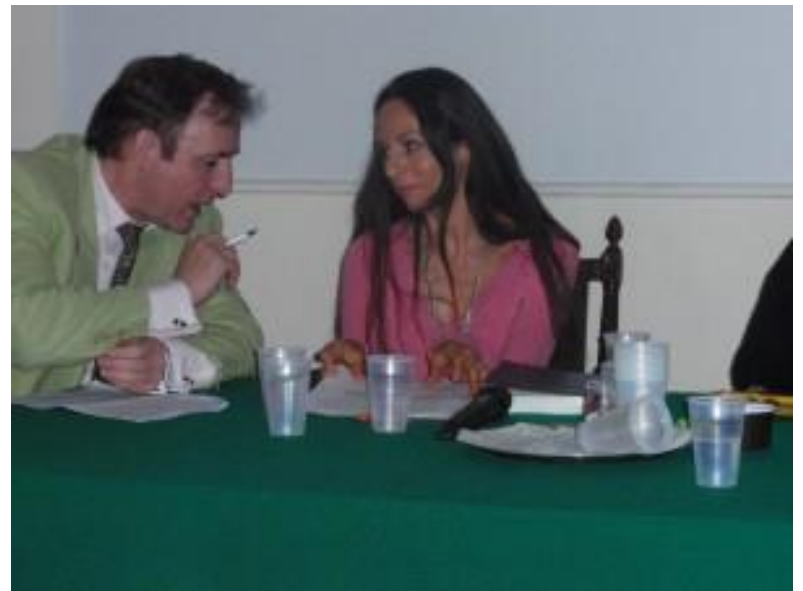

2. Professor Barbara Weber \& Professor Andrew Wierciński at the May-Symposium, referring to the hermeneutical origins of philosophical education.

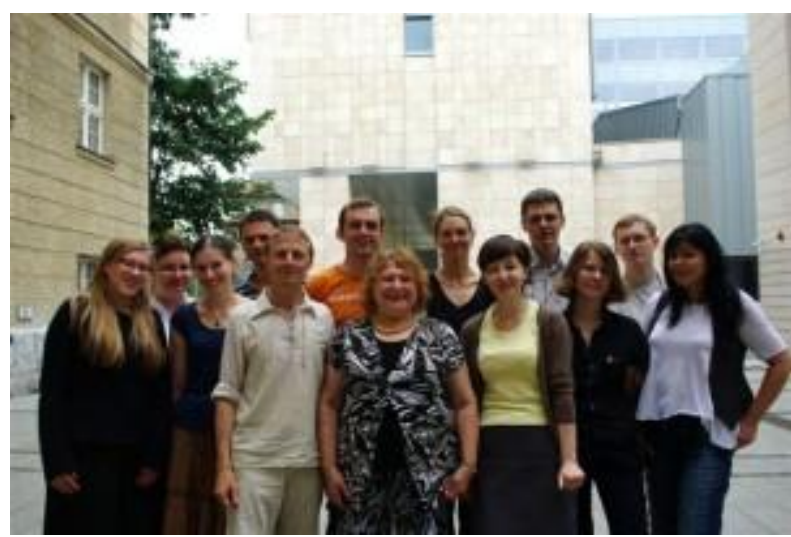

3. Participants of the August-Workshop ?Children Philosophize II? (Professor Eva Marsal in the middle).

The 2nd volume (2010/11) of Ethics in Progress Quarterly is focused on the research background that is representative for initiatives. It includes the methodological papers from Takara Dobashi (Hiroshima, Japan), Roberto Franzini Tibaldeo (Pisa, Italy), Matthew Lipman (+ 2010, New Jersey, U.S.A.), Ekkehard Martens (Hamburg, Germany), Eva Marsal (Karlsruhe,

Germany), Barbara Weber (Vancouver, Canada / Regensburg, Germany), and Eva Zoller Morf (Kreuzlingen, Switzerland). In the Polish Bonus we present Ekkehard Martens? Chapter from his recent German book Philosophieren mit Kindern, Stuttgart, 2002 (?Children are Philosophers, Philosophers are Children?, pp. 44-52), and the cooperative paper ?Imagination, Emotions, Reflection. Fables as Teaching Instrument for Ethics Teachers?) from Ewa Nowak?s research group (Poznań, Poland).

This number of EPQ (and both worhshops and symposia we have reported on) have been granted by Mayor of Poznan Ryszard Grobelny, Vice-Rector of AMU Jacek Witkoś, Head of Dept. of Social Sciences Zbigniew Drozdowicz, and Director of Institute of Philosophy AMU Tadeusz Buksiński. Our thanks are also going to PhD Lucy Cayard, PhD Gerald Taylor, and PhD Boris Zizek. 